\title{
DINÂMICA DE USO DA TERRA, NO SETOR AGROPECUÁRIO, EM PARAGOMINAS - PA
}

\author{
Felipe Souza Carvalho1; Kelly Nayara Nascimento Thompson²; Wilkson Antonionne Sá Lima ${ }^{3}$; Márcio Roberto \\ da Silva Melo ${ }^{4}$; Núbia de Fátima Alves Santos ${ }^{5}$; Luciana da Silva Borges ${ }^{6}$; Vitor Quintela de Souza ${ }^{7}$; Amaralina \\ Celoto Guerreiro 8 .

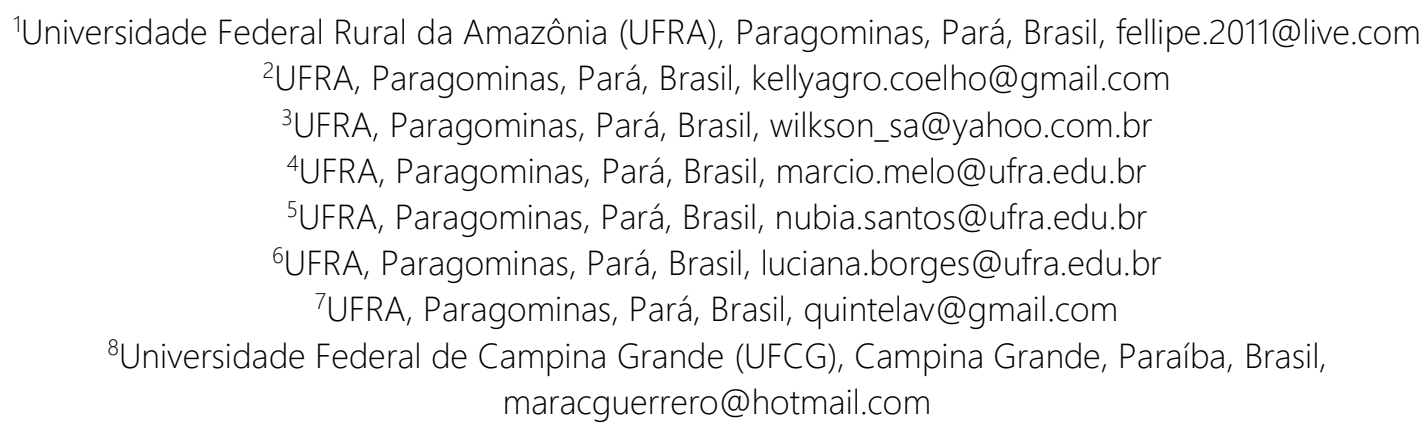

RESUMO: Conhecer o uso da terra apresenta-se como passo essencial para planejamento estratégico do setor agropecuário. Dessa forma, este estudo avaliou a dinâmica de uso da terra, do setor agropecuário, no município de Paragominas - PA, no período de 2008 a 2014, por meio de técnicas de geoprocessamento e do modelo shift-share. As fontes da base de dados adquiridos foram do Projeto TerraClass, DNIT e IBGE, obtidos em seus endereços eletrônicos de forma gratuita, os quais foram utilizados na elaboração de mapas georreferenciados. As classes de usos da terra analisadas foram agricultura anual, pasto sujo, pasto limpo, desflorestamento e reflorestamento nos anos de 2008 e 2014. Os dados em hectares provenientes das cinco classes de uso da terra também foram analisados pelo modelo shift-share através do efeito área decomposto nos efeitos escala e substituição. Os resultados revelaram que uso da terra em Paragominas apresentou expansão para as atividades pasto limpo e agricultura anual no período de estudo resultando em valores positivos do efeito escala. As atividades pasto sujo e desflorestamento revelaram uma diminuição de área utilizada o que resultou em valores negativos do efeito substituição. A classe que apresentou maiores valores em hectares utilizados e de efeito substituição foi o pasto limpo.

PALAVRAS-CHAVE: Amazônia, Geoprocessamento, Modelo Shift-Share.

\section{DYNAMICS OF LAND USE, ON AGRICULTURAL SECTOR, IN PARAGOMINAS, PARÁ STATE}

ABSTRACT: Knowing land use is an essential step for strategic planning of the agricultural sector. Thus, this study evaluated the dynamics of land use in the city of Paragominas from 2008 to 2014 using geoprocessing and the shift-share model. The sources of the database acquired were TerraClass project, DNIT and IBGE, obtained in electronic addresses for free, 
which were used in the elaboration of georeferenced maps. The land uses were annual crops, shrubby pasture, herbaceous pasture, deforestation and reforestation, on the years of 2008 and 2014. The data in hectares from the five land use classes were also analyzed by the shift-share model through the effect area decomposed into the scale and substitution effects. The results revealed that land use in Paragominas presented expansion to the activities herbaceous pasture and annual crops in the study period resulting in positive values of the scale effect. Shrubby pasture and deforestation activities revealed a decrease in area utilization which resulted in negative values of the substitution effect. The class that presented higher values in hectares used and of substitution effect was the herbaceous pasture.

KEYWORDS: Amazon, Geoprocessing, Shift-share Model.

\section{DINÁMICA DE USO DE LA TIERRA, EN EL SECTOR AGROPECUARIO, EN PARAGOMINAS - PA}

RESUMEN: Conocer el uso de la tierra se presenta como paso esencial para la planificación estratégica del sector agropecuario. De esta forma, este estudio evaluó la dinámica de uso de la tierra, del sector agropecuario, en el municipio de Paragominas en el período de 2008 a 2014 por medio de técnicas de geoprocesamiento y del modelo shift-share. Las fuentes de la base de datos adquiridos fueron del Proyecto TerraClass, DNIT e IBGE, obtenidos en sus direcciones electrónicas de forma gratuita, los cuales fueron utilizados en la elaboración de mapas georreferenciados. Las clases de usos de la tierra analizadas fueron agricultura anual, pasto sucio, pasto limpio, deforestación y reforestación en los años 2008 y 2014. Los datos en hectáreas provenientes de las cinco clases de uso de la tierra también fueron analizados por el modelo shift-share a través del efecto área descompuesto en los efectos de escala y sustitución. Los resultados revelaron que el uso de la tierra en Paragominas presentó expansión para las actividades pasto limpio y agricultura anual en el período de estudio resultando en valores positivos del efecto escala. Las actividades pasto sucio y deforestación revelaron una disminución de área utilizada que resultó en valores negativos del efecto sustitutivo. La clase que presentó mayores valores en hectáreas utilizadas y de efecto sustitutivo fue el pasto limpio.

PALABRAS CLAVE: Amazonia, Geoprocesamiento, Modelo Shift-Share.

\section{INTRODUÇÃO}

O Brasil é um dos maiores produtores

de alimentos do mundo. Resultado do processo de modernização pelo qual passou o setor agropecuário brasileiro em prol do desenvolvimento de estratégias capazes de otimizar a utilização dos recursos naturais, o que possibilitou ao 
país figurar entre os líderes na produção de diversos segmentos do setor, a exemplo da produção de grãos e pecuária bovina (DIAS-FILHO, 2011; SAATH, 2016).

A abertura de novos mercados, produto dessa visibilidade internacional, aliada a crescente demanda mundial por alimentos em decorrência do aumento populacional, desencadeou no país um processo de competição pelo uso da terra, principalmente entre as atividades produtoras de commodities agropecuários, uma vez que a estratégia para o aumento de produção, por adição de novas áreas, tornou-se inviável devido ao maior controle sobre os danos ambientais causados por estas atividades (MARTHA JÚNIOR, 2015; MELO, 2017).

Diante desse cenário, foi evidente, na última década, o deslocamento de algumas atividades para fora dos seus redutos de produção. Na região amazônica, além da grande e crescente população, encontra-se uma economia agropecuária que corresponde por 14\% das atividades agropecuárias desenvolvidas em todo o país, onde o estado do Pará assume posição de destaque sendo detentor $9,4 \%$ do rebanho bovino do país, além de produzir mais de 9,1 milhões de toneladas de produtos agrícolas, o que corresponde a 27\% do PIB agropecuário do estado (IBGE, 2016). No entanto, este crescimento do setor agropecuário na região foi historicamente caracterizado pela expansão de novas áreas, fazendo com que o desmatamento tenha se intensificado, principalmente, através do extrativismo madeireiro e subsequentemente com práticas agropecuárias (CATANEO, 2002; SAWYER, 2008; FRAGATA; BARRETO, 2016).

Embora a bovinocultura seja a principal atividade agropecuária desenvolvida no Estado, seus baixos índices produtivos, resultantes de um modelo onde a mesma ainda é praticada majoritariamente de maneira extensiva, em grandes áreas, a torna vulnerável as investidas, por novas áreas, de outras atividades do setor, como é o caso da agricultura, que com melhor aproveitamento de área e de insumos proporciona melhores índices de produtividade, o que implica em modificações constantes na paisagem (VALENTIM; ANDRADE, 2009). 
Assim, conhecer o uso da terra a respeito da divisão do espaço geográfico apresenta-se como passo essencial para planejamento estratégico do setor agropecuário. O uso de técnicas de sensoriamento remoto e geoprocessamento constitui estratégia eficaz no fornecimento de informações relevantes do uso e cobertura da terra (RUDORFF et al., 2010; BATISTELLA et al., 2011), pois permitem analisar, através de imagens, a distribuição espacial de áreas cultivadas, e identificar as possíveis modificações ocorridas na cobertura vegetal em diversas épocas (MELO, 2017).

O modelo shift-share (modelo diferencial-estrutural) é uma opção de análise dos dados não espaciais, para estudo da dinâmica de usos de terra ao longo de um determinado período de tempo. O Modelo Shift - Share é conhecido como uma importante ferramenta utilizada em conjunto com os estudos de geoprocessamento, especialmente, quando se trata da análise de mudança do uso da terra (FILGUEIRAS, 2015). Dessa forma, o objetivo desta pesquisa foi estudar a dinâmica de uso da terra, no setor agropecuário, em Paragominas - PA, no período de 2008 a 2014, por meio de técnicas de geoprocessamento e do modelo shiftshare.

\section{MATERIAL E MÉTODOS}

O estudo foi desenvolvido no município de Paragominas, localizado na mesorregião sudeste do estado do Pará, situado a $2^{\circ} 59^{\prime} \mathrm{S}$ e $47^{\circ} 21^{\prime} \mathrm{O}$, com altitude média de 89 m e interceptado pelas rodovias PA-125, PA-256, PA-140, PA263, PA-108 e BR-010 (Figura 1). O clima é classificado como Awi, segundo Köppen, com médias anuais de precipitação, umidade relativa e temperatura de 1.743 $\mathrm{mm}, 81 \%$ e $26,3{ }^{\circ} \mathrm{C}$, respectivamente, onde o período de julho a novembro é considerado de baixa disponibilidade hídrica (ALVES et al., 2014; IBGE, 2017). 
Figura 1. Localização da área de estudo.

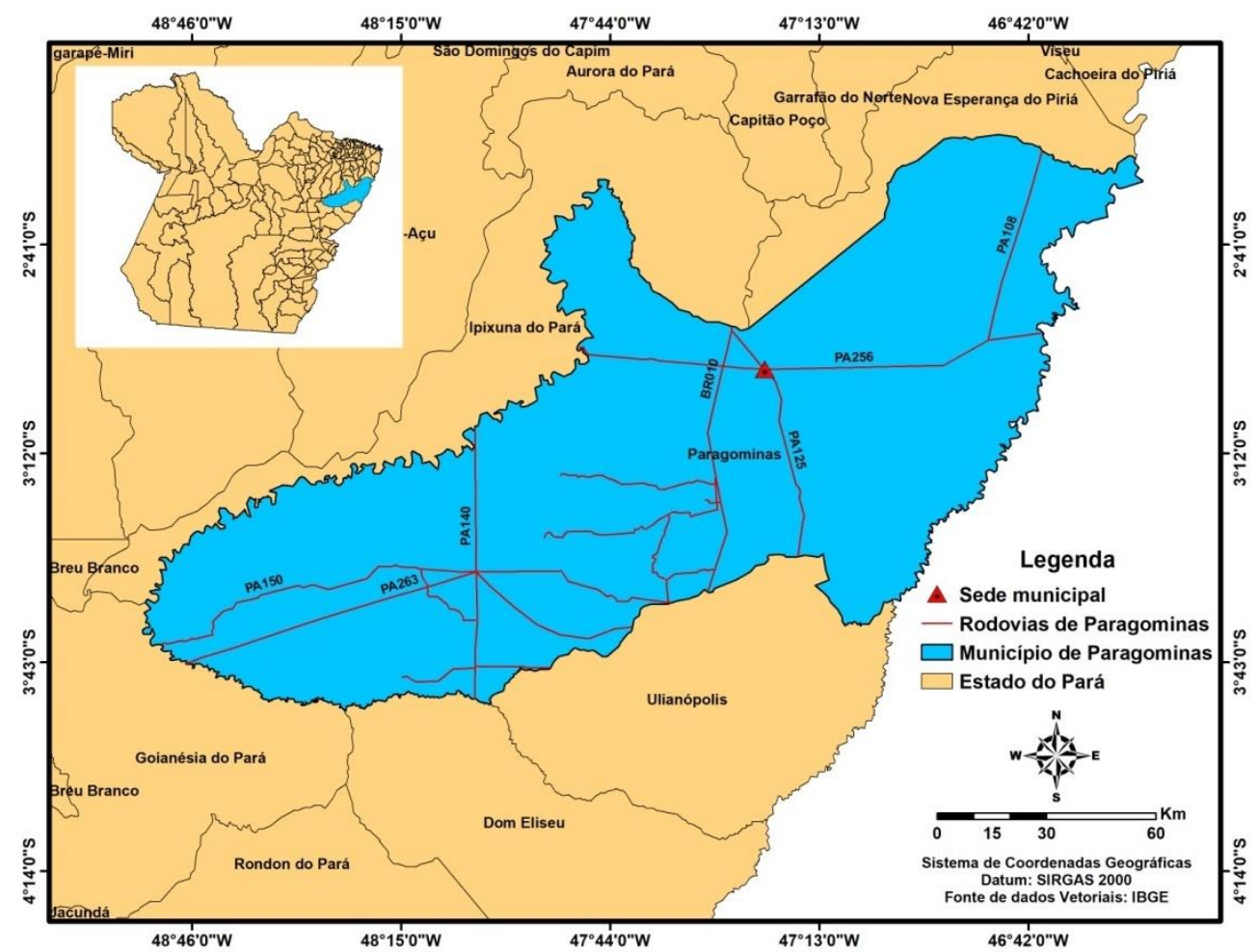

Fonte: Elaborado pelos autores.

Os dados de uso da terra do município foram obtidos do Projeto TerraClass na forma de arquivo shapefile que possui informações de posição, forma e feições geográficas, disponibilizadas no endereço eletrônico Instituto nacional de Pesquisas Espaciais - INPE (ALMEIDA et al., 2016). As variáveis extraídas deste projeto para análise neste estudo totalizam o número de cinco tipos de usos da terra e denominam-se agricultura anual, pasto sujo, pasto limpo, desflorestamento e reflorestamento para o intervalo de tempo compreendido entre os anos de 2008 e 2014. Os demais alvos do projeto compuseram uma única classe denominada outros usos.

As rodovias que interceptam 0 município foram adquiridas através de arquivos shapefile baixados no site do Departamento Nacional de Infraestrutura de Transportes (DNIT).

Os dados estatísticos de efetivo bovino (2008 e 2014), bem como arquivos shapefile com as delimitações geográficas do Brasil, Pará e Paragominas foram 
obtidos no site do Instituto Brasileiro de Geografia e Estatística (IBGE). Todos estes dados foram adquiridos de forma legal e gratuita.

O procedimento metodológico deste estudo foi dividido em três etapas: Aquisição dos dados, tratamento dos dados com aplicação de técnicas de SIG e aplicação do modelo shift-share.

A primeira etapa consistiu na aquisição de dados que foi realizada através de downloads de arquivos online das bases do Projeto TerraClass, DNIT e IBGE. Vale ressaltar que os dados (shapefiles) do projeto TerraClass foram extraídos das cenas identificadas pelas órbitas-ponto 223/62, 222/62, 223/63 e 222/63, que correspondem aos limites geográficos do município de Paragominas - PA, dos anos de 2008 e 2014.

O tratamento inicial dos arquivos vetoriais realizados na segunda etapa, consistiu no recorte das quatro cenas que limitam o município, através da ferramenta Clip (Recortar) no programa ArcGis. $\bigcirc$ recorte destes arquivos shapefile foi essencial para obtenção do valor em hectares de área utilizada para cada tipo de uso da terra em Paragominas nos anos analisados. As informações de área, em hectares, estavam contidas na Atribbute Table (Tabela de Atributos) de todos os arquivos shapefile e a ferramenta Sellect By Attributes (Seleção por Atributos) foi utilizada para selecionar unicamente os cinco usos da terra de interesse neste estudo, as quais foram espacializadas através de mapas geográficos. Para se conhecer o valor em hectares, de cada classe de uso da terra existente nos dados digitais, utilizou-se a ferramenta Calculate Geometry (Calcular Geometria).

A terceira e última etapa metodológica deste estudo foi realizada com a aplicação do modelo shift-share. Os dados obtidos anteriormente, das classes floresta, agricultura anual, pasto sujo, pasto limpo, desflorestamento e reflorestamento foram tabuladosem planilhas do programa Excel, sendo as mesmas aplicadas ao modelo shift-share.

O modelo shift-share neste estudo considerou o Efeito Área (EA) e sua decomposição em Efeito Escala (EE) e Efeito Substituição (ES). O EE mensura alterações de tamanho ou escala dos sistemas podendo ocorrer expansão ou 
contração do mesmo, enquanto que o ES identifica as atividades que substituíram ou foram substituídas por outras dentro do sistema estudado (AGUIAR; SOUZA, 2014; GARCIA; BUAINAIN, 2016).

Os dados dos anos de estudo inseridos no modelo foram $T_{1}$ (2008) e T 2 (2014), e a expressão analítica do mesmo é descrita como segue:

$A i_{2}-A i_{1}=\left(\alpha A i_{1}-A i_{1}\right)+\left(A i_{2}-\alpha A i_{1}\right), e m$ que:

$A i_{2}-A i_{1}=$ Variação da área cultivada com uma classe de uso da terra específica "i", entre período $T_{1}$ e $T_{2}$;

$\left(\alpha A i_{1}-A i_{1}\right)=$ efeito - escala;

$\left(A i_{2}-\alpha A i_{1}\right)=$ efeito - substituição;

Sendo: $\alpha=A T_{1}$ (Equação 1)/AT (Equação

2):

$$
\begin{aligned}
& \text { Equação (1) } \quad \text { Equação (2) } \\
& A T 1=\sum_{i=1}^{n} A i 1 \quad A T 2=\sum_{i=1}^{n} A i 2
\end{aligned}
$$

Sendo que Ai corresponde à área cultivada com ai-ésima classe de uso; i =
$1,2,3 \ldots, n$ classes analisadas; $\mathrm{AT}_{1}$ é o tamanho do sistema de área ocupada no período do ano 2008; AT 2 é o tamanho do sistema de área ocupada no período do ano 2014; $\alpha$ é a relação entre $A T_{1}$ e $A T_{2}$, que mede a alteração do tamanho do sistema de áreas ocupadas e no período de estudo.

\section{RESULTADOS E DISCUSSÃO}

Após análise dos dados, foi possível observar que as atividades de agricultura, de reflorestamento e de pasto limpo apresentaram crescimento entre os anos analisados. Por outro lado, neste mesmo período, as atividades de desflorestamento e pasto sujo apresentaram redução em suas áreas, sendo este ultimo, passando de 276.000 ha no ano de 2008 para 52.000 ha em 2014. Em contrapartida o pasto limpo apresentou aumento de mais de 200\%, tendo em 2008 aproximadamente 71.000 ha e em 2014 ultrapassou o valor de 333.000 ha (Figura 2). 
Figura 2. Variação de área (mil hectares) no período de 2008 e 2014 para cada atividade desenvolvida.

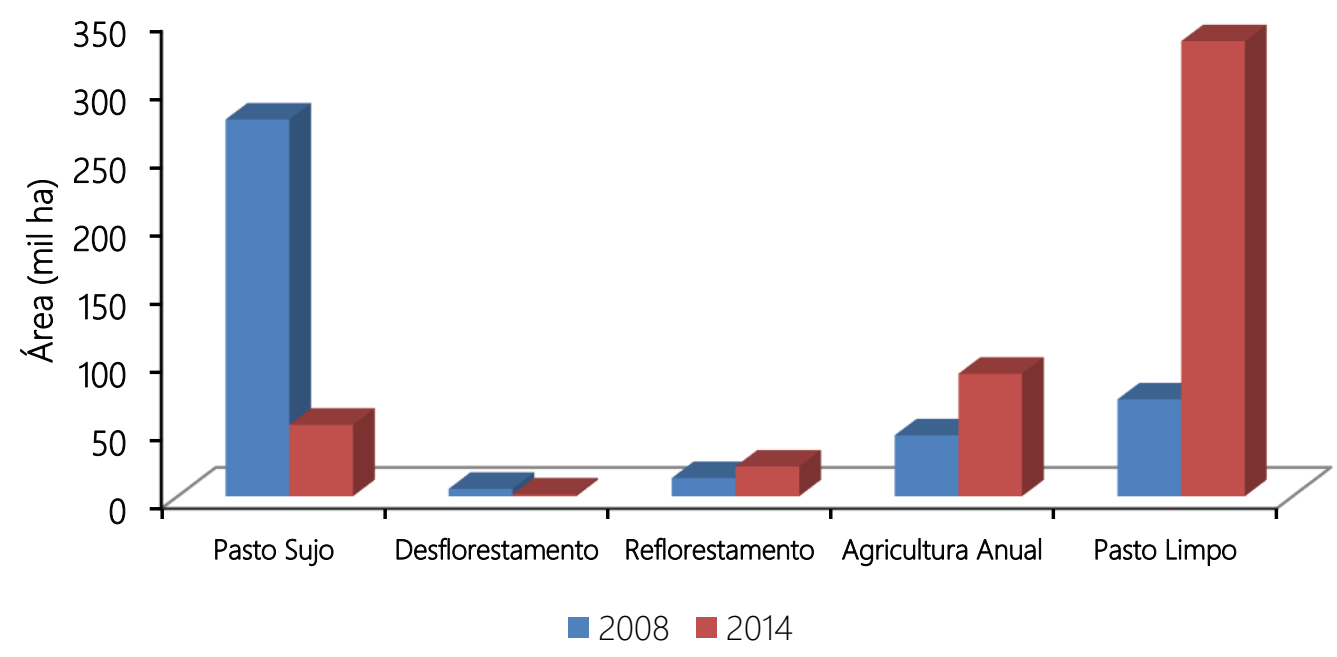

Fonte: Elaborado pelos autores.

Estas alterações de redução e aumento de áreas destinadas a pasto sujo e limpo, respectivamente, podem ser explicadas pelas mudanças no cenário do agronegócio em Paragominas, onde pastagens consideradas sujas foram convertidas em agricultura, devido a maior rentabilidade oriunda do mercado de grãos, cuja a produtividade por hectare é mais elevada quando comparada a atividade pecuária haja vista que o retorno financeiro dos investimentos para renovação ou recuperação das pastagens são obtidos a longo prazo.

O aumento e redução das áreas de reflorestamento e desflorestamento, respectivamente, pode ser atribuído ao fato do município de Paragominas ter aderido ao Programa Municípios Verdes PMV, lançado em 2011, que tem como premissa fortalecer a produção rural sustentável por meio de ações estratégicas de ordenamento ambiental e fundiário através do combate ao desmatamento, recuperação das matas ciliares e áreas desflorestadas ilegalmente (PMV, 2017).

A distribuição espacial dessas mudanças ocorridas no uso da terra em Paragominas é apresentada nas Figuras 3 e 4 para os anos de 2008 e 2014, respectivamente, que mostra um comparativo de como o município se encontrava no ano inicial e final do estudo. 
Figura 3. Mapa do uso da terra no município de Paragominas no ano de 2008.

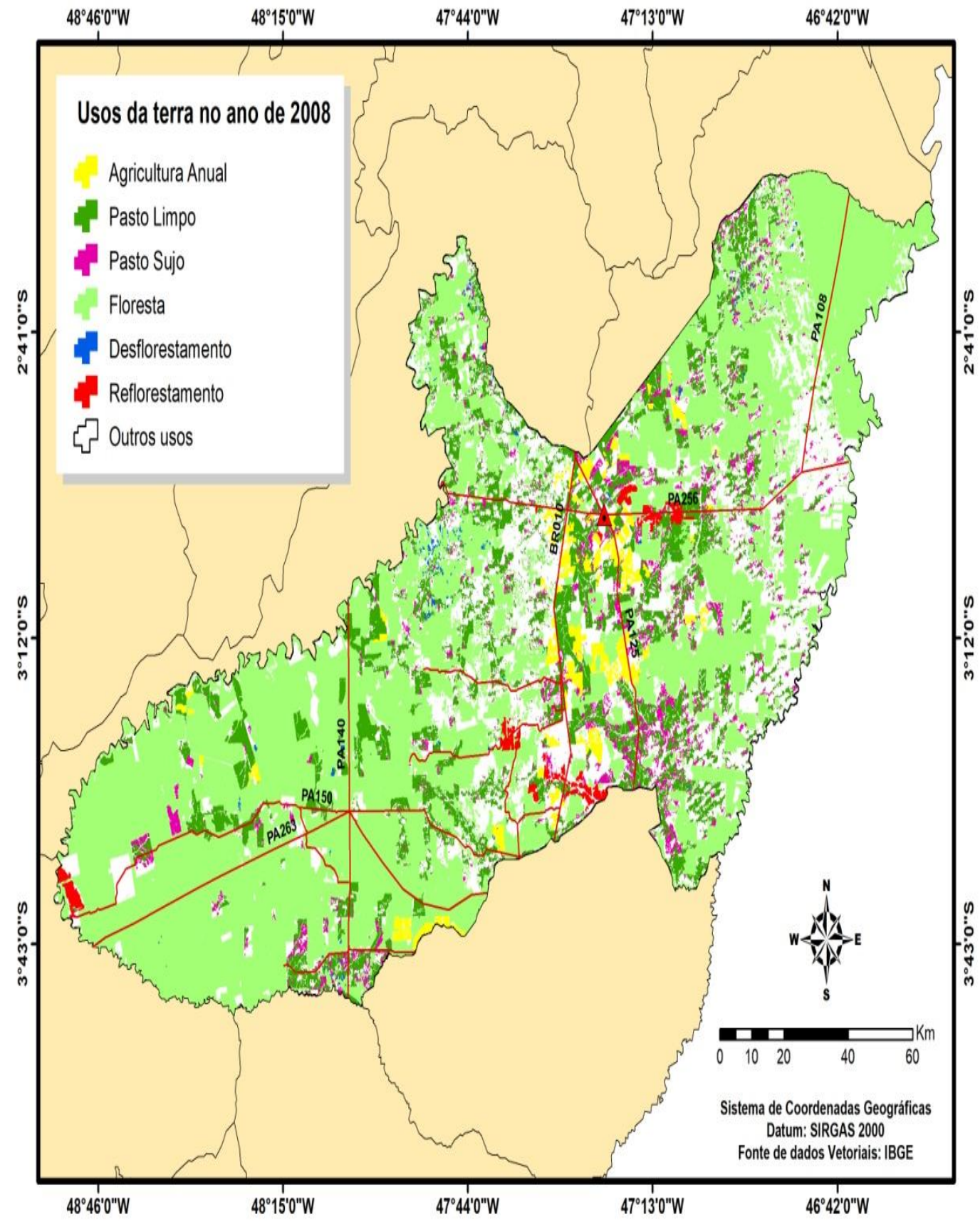

Fonte: Elaborado pelos autores. 
Figura 4. Mapa do uso da terra no município de Paragominas no ano de 2014.

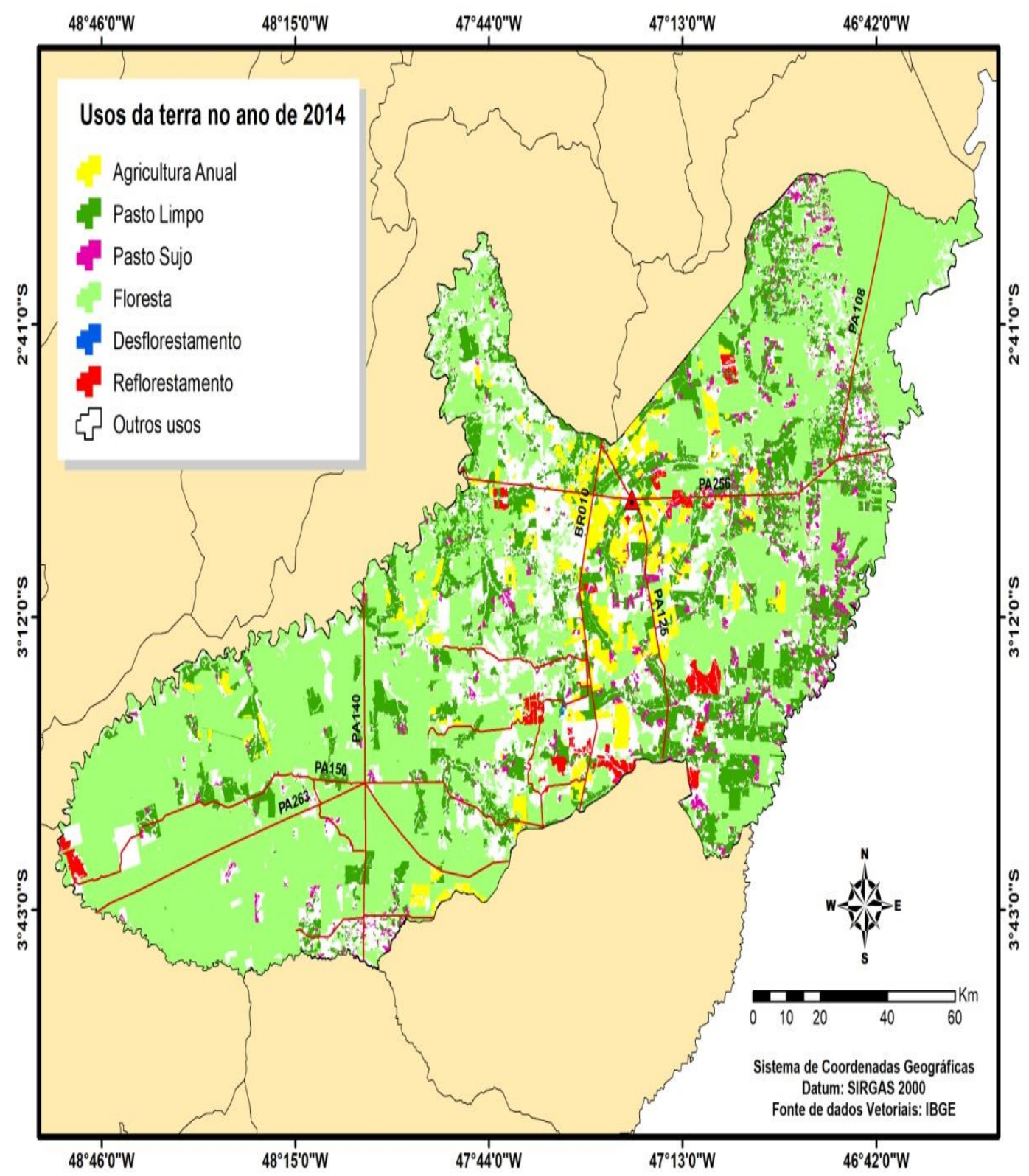

Fonte: Elaborado pelos autores.

Na análise do modelo shift-share, o efeito área (EA) determinou as variações de área (ha) de uso da terra no município de Paragominas entre as atividades estudadas, sendo este decomposto nos efeitos escala e substituição, onde o primeiro avaliou a variação do sistema produtivo como um todo, em hectares, para cada atividade desenvolvida em determinado período e quais destas 
atividades cederam ou incorporaram áreas entre si através do efeito substituição.

O efeito escala (EE) estimou como a área de uso da terra entre as classes analisadas, poderia ter se alterado, em virtude da variação na área total do sistema, caso essa variação se distribuísse de modo uniforme entre todas as classes ou atividades desenvolvidas (LOURENZANI; CALDAS, 2014; SOUZA; WANDER, 2014). uso da terra no município, para as classes estudadas, apresentou variação positiva, no período de 2008 a 2014, como mostra os valores do efeito escala, evidenciado pela expansão da área total utilizada pelo sistema, apresentando aumento de pouco mais de 88 mil hectares, sendo este acréscimo relacionado ao desenvolvimento dos usos para a agricultura anual, reflorestamento e pasto limpo, o que pode ter contribuído para o fortalecimento do sistema produtivo na região (Tabela 1).

Tabela 1. Decomposição do Efeito Área em Efeito Escala e Substituição no período de 2008 a 2014.

\begin{tabular}{|c|c|c|c|c|c|c|}
\hline \multirow[t]{2}{*}{ Paragominas } & \multicolumn{2}{|c|}{ Área cultivada (ha) } & \multicolumn{2}{|c|}{ Variação de Área } & \multirow{2}{*}{$\begin{array}{c}\mathrm{EE} \\
\text { (ha) }\end{array}$} & \multirow{2}{*}{$\begin{array}{c}\text { ES } \\
\text { (ha) }\end{array}$} \\
\hline & 2008 & 2014 & (ha) & $(\%)$ & & \\
\hline Pasto Sujo & $276.191,54$ & $52.498,57$ & $-223.692,96$ & $-80,99$ & $59.391,08$ & $-283.084,05$ \\
\hline Desflorestamento & $5.480,33$ & $1.332,64$ & $-4.147,69$ & $-75,68$ & $1.178,47$ & $-5.326,15$ \\
\hline Reflorestamento & $13.374,03$ & $21.836,55$ & $8.462,51$ & 63,28 & $2.875,90$ & $5.586,62$ \\
\hline Agricultura Anual & $44.705,27$ & $89.802,96$ & $45.097,69$ & 100,88 & $9.613,24$ & $35.484,45$ \\
\hline Pasto Limpo & $71.040,90$ & $333.656,38$ & $262.615,47$ & 369,67 & $15.276,34$ & $247.339,13$ \\
\hline TOTAL & $410.792,08$ & $499.127,10$ & $88.335,02$ & 21,50 & & \\
\hline
\end{tabular}

Fonte: Elaborado pelos autores.

Os valores de variação de área para pasto sujo e pasto limpo apresentaram maior representatividade na variação de área do sistema, ocasionando mudanças do uso da terra no município, de acordo com os dados de variação de área (Tabela 1).

O efeito substituição (ES) representa a participação das classes dentro do sistema, apresentando quais categorias 
absorveram ou cederam área no mesmo.

Analisando os resultados obtidos, foi observado que as classes pasto limpo, agricultura anual e reflorestamento corresponderam aos usos que apresentarem ES positivo, o que indica absorção de área das classes que expuseram ES negativo, sendo estas, pasto sujo e desflorestamento (Tabela 1).
De acordo com análise da decomposição do ES negativo, verificando a interação entre as classes do sistema, foi observado que a classe pasto sujo compreendeu 98\% do total de área cedida, onde 242.771,45 hectares foram absorvidos pela classe pasto limpo, 34.829,15 pela atividade agrícola, e $5.483,45 h a$ absorvidos pela classe reflorestamento (Tabela 2).

Tabela 2. Dinâmica das atividades ligadas ao setor agropecuário entre anos de 2008 e 2014 em Paragominas - PA.

\begin{tabular}{cccccc}
\hline \multirow{2}{*}{$\begin{array}{c}\text { Classes que } \\
\text { cederam área (ha) }\end{array}$} & \multicolumn{2}{c}{ Classes que incorporaram área (ha) } & \multicolumn{2}{c}{$\begin{array}{c}\text { Área total } \\
\text { (Ha) }\end{array}$} & $\begin{array}{c}\text { Área total } \\
(\%)\end{array}$ \\
\cline { 2 - 5 } Pasto sujo & $\begin{array}{c}\text { Agricultura } \\
\text { Anual }\end{array}$ & Reflorestamento & $\begin{array}{c}\text { Pasto } \\
\text { limpo }\end{array}$ & & 98.15 \\
Desflorestamento & $34.829,15$ & $5.483,45$ & $242.771,45$ & $283.084,05$ & 1.85 \\
\hline Total (ha) & 655,30 & 103,17 & $4.567,68$ & $-5.326,15$ & $-288.410,20$ \\
\hline
\end{tabular}

Fonte: Elaborado pelos autores.

A classe pasto limpo apresentou 0 maior ES positivo, com aumento de área de 242.771,45 ha provenientes de pasto sujo e 4.567,68 ha de área de desmatamento. Este aumento pode ser atribuído ao novo modelo de produção pecuária adotado pelo município, denominado pecuária verde, que, dentre outros requisitos, preconiza a utilização de técnicas mais adequadas no preparo de área e manejo das pastagens, bem como no investimento com animais de elevado padrão genético, que em áreas menores apresentam maiores índices zootécnicos. Tal afirmativa pode ser confirmada através do rebanho bovino, que reduziu de 418.976 cabeças para 358.652 cabeças, no município de Paragominas, durante o período analisado (IBGE, 2016). 
A classe agricultura anual apresentou ES positivo o que expressa crescimento da atividade, resultante da absorção de $34.829,15$ ha oriundos da classe pasto sujo e 655,30 ha da classe desflorestamento (Tabela 2). Este aumento de área tem no cultivo da soja seu principal propulsor, haja vista que entre os anos de 2008 e 2014 a área plantada de soja, no município de Paragominas, passou de 11.720 ha para 42.000 ha, tornando-o segundo maior produtor de soja do estado do Pará (BARBOSA, 2015).

De acordo com os resultados do ES, a expansão da classe agricultura anual ocorreu majoritariamente em áreas ocupadas anteriormente com pastagem suja, localizadas, principalmente, às margens das rodovias, o que propicia a logística no escoamento da produção (Figura 5).

Figura 5. Substituição da pastagem por atividade agrícola entre os anos de 2008 e 2014.

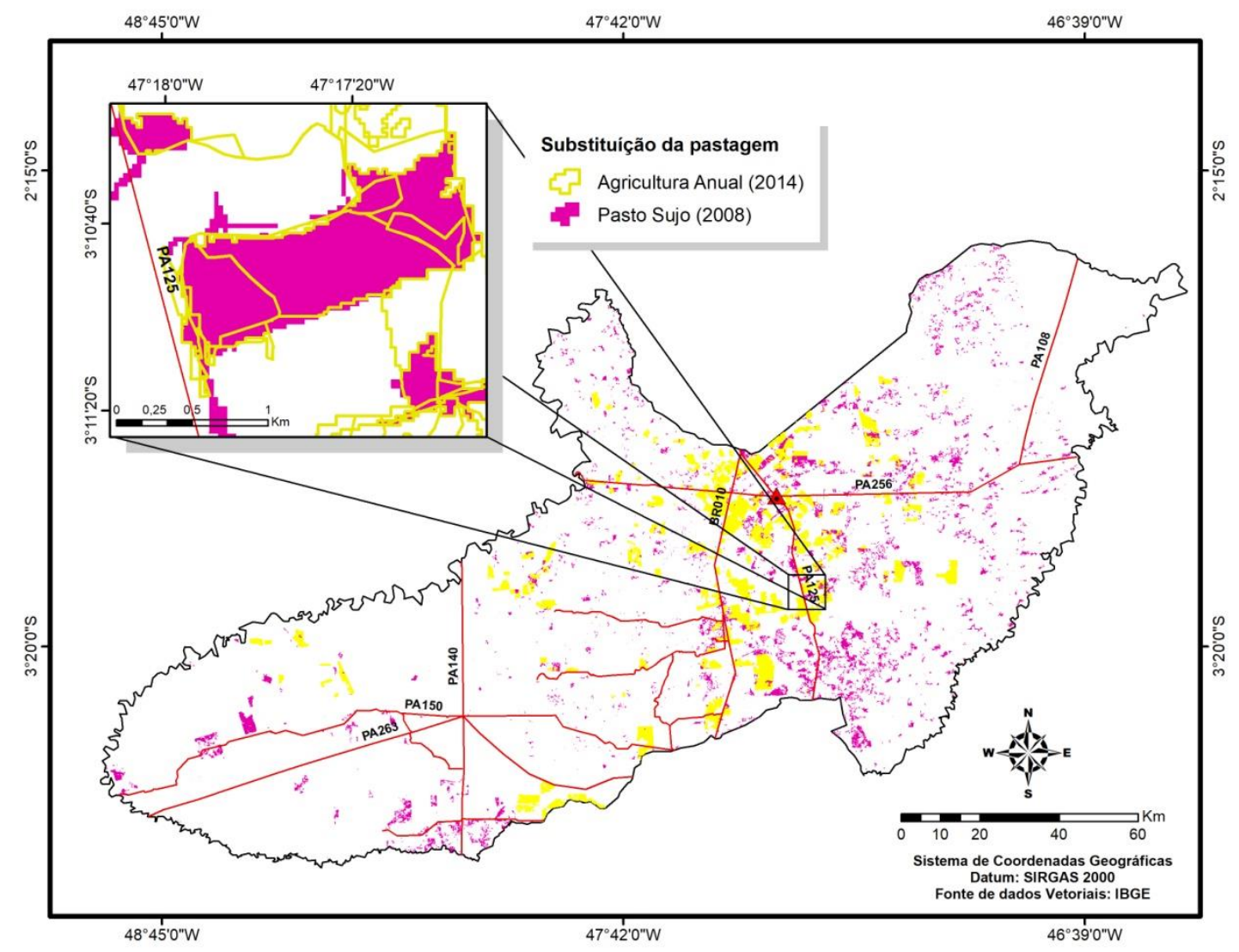

Fonte: Elaborado pelos autores. 
Além disso, os baixos rendimentos das áreas de pastagem suja atrelados ao elevado custo de manutenção e renovação das mesmas contribuíram para este processo de substituição. Entretanto, esta mudança do uso da terra não é definitiva, uma vez que grande parte desta dinâmica ocorre por meio do processo de arrendamento que, além de possibilitar o crescimento da atividade agrícola, proporciona a reestruturação físico-química do solo através dos resíduos derivados do cultivo agrícola (SILVA et al., 2016).

Esta prática consiste em uma alternativa comumente adotada através dos sistemas de integração lavourapecuária que permitem a redução dos custos com implantação das pastagens, devido a menor utilização de fertilizantes, bem como aproveitamento da calagem e correção do solo realizado por ocasião do plantio das culturas agrícolas, como milho, soja e outras, permitindo assim a formação de pastagens de alta qualidade e valor nutritivo (CORDEIRO et al., 2015; SILVA; SALES; VELOSO, 2016).

\section{CONCLUSÃO}

O uso da terra em Paragominas apresentou uma expansão no sistema como um todo, resultando em valores positivos do efeito escala, com destaque para as classes pasto limpo e agricultura anual no período analisado.

As atividades pasto sujo e desflorestamento revelaram uma redução de área, em função destas atividades terem cedido área para outras classes, no período analisado. A atividade pasto sujo foi a que mais cedeu área para as demais classes. De acordo com o efeito substituição, as classes que mais incorporaram área foram às atividades pasto limpo e agricultura anual.

○ estudo revelou que 0 desenvolvimento das atividades pasto limpo e agricultura anual estão atrelados a dois fatores que são a proximidade das rodovias estaduais e federais e a consolidação do sistema integração lavoura pecuária que tem sido amplamente difundido na região do município de Paragominas. 


\section{REFERÊNCIAS}

AGUIAR, C. J.; SOUZA, P. M. Impactos do crescimento da produção de cana-deaçúcar na agricultura dos oito maiores estados produtores. Revista Ceres [online]. v.61, n.4, pp.482-493, jul/ago, 2014.

AlMEIDA, C. A.; COUTINHO, A. C.; ESQUERDO, J. C. D. M.; ADAMI, M.; VENTURIERI, A.; DINIZ, C. G.; DESSAY, N.; DURIEUX, L.; GOMES, A. R. High spatial resolution land use and land cover mapping of the Brazilian Legal Amazon in 2008 using Landsat-5/TM and MODIS data. Acta Amazonica, v. 46, n. 3, p. 291302, 2016.

AlVES, L. W. R.; CARVAlHO, E. J. M., SILVA, L. G. T. Diagnóstico agrícola do município de Paragominas, PA /. - Belém, PA: Embrapa Amazônia Oriental (Boletim de pesquisa e desenvolvimento/ Embrapa Amazônia Oriental, ISSN 1983-0483; 26 p., 2014.

BARBOSA, M. Z. Fronteira Agrícola: a soja na Amazônia Legal. Instituto de economia agricola. Jan/2015. Disponível em:http://www.iea.sp.gov.br/out/LerText o.php?codTexto=13575. Acesso em: 22 de fevereiro de 2017.

BATISTELLA, M.; ANDRADE, R. G.; BOLFE, E. L.; VICTORIA, D. C.; SILVA, G. B. S. Geotecnologias e gestão territorial da bovinocultura no Brasil. Revista Brasileira de Zootecnia, v.40, supl. especial, p.251260, 2011.

CATANEO, A. Balancing Agricultural Development and Deforestation in the Brazilian Amazon. International Food
Policy Research Institute. Research Report. 129, 158p. 2002.

CORDEIRO, L. A. M.; VILELA, L.; MARCHAO, R. L.; KLUTHCOUSKI, J.; MARTHA JÚNIOR, G.B. Integração lavoura-pecuária e integração lavourapecuária-floresta: estratégias para intesificação sustentável do uso do solo. Cadernos de Ciência \& Tecnologia, v. 32, p. 15-53, 2015.

DIAS-FILHO, M. B. Os desafios da produção animal em pastagens na fronteira agrícola brasileira. Revista Brasileira de Zootecnia, v.40, p.243-252. (supl. especial). 2011.

FILGUEIRAS, G. C. Fontes de crescimento do setor agrícola no Estado do Pará, Avaliação pelo método SHIFT-SHARE. Crescimento Agrícola. 23 set. 2015. Disponível em: http://www.researchgate.net/publication/ 242213508. Acesso em: 11 de março de 2017.

FRAGATA, R. A.; BARRETO, W. Z. Um panorama sobre a produção agropecuária na mesorregião do Baixo Amazonas. Revista Observatorio de la Economía Latinoamericana, Brasil, (outubro 2016). En línea: http://www.eumed.net/cursecon/ecolat/b r/16/mesorregiao.html.

GARCIA, J. R.; BUAINAIN, A. M. Dinâmica de Ocupação do Cerrado Nordestino pela Agricultura: 1990 e 2012. Revista de Economia e Sociologia. Rural, Brasília, v. 54, n. 2, p. 319-338, 2016.

IBGE. INSTITUTO BRASILEIRO DE GEOGRAFIA E ESTATÍSTICA. Sistema de Recuperação Automática (SIDRA). 
Pesquisa Agrícola Municipal 2016.

Disponível em: www.sidra.ibge.gov.br/. Acesso em: 22 de fevereiro de 2017.

IBGE. INSTITUTO BRASILEIRO DE GEOGRAFIA E ESTATÍSTICA. Disponível em:

http://downloads.ibge.gov.br/downloads _geociencias.htm >. Acesso em: 22 de fevereiro de 2017.

LOURENZANI, W. L.; CALDAS, M.M. Mudanças no uso da terra decorrentes da expansão da cultura da cana-de-açúcar na região oeste do estado de São Paulo. Ciência Rural, Santa Maria, v. 44, n. 11, p. 1980-1987, Nov. 2014.

MARTHA JÚNIOR, G.B. Pesquisa, desenvolvimento e inovação na agropecuária. Revista de Politica Agrícola, v. 24, p. 117-119, 2015.

MELO, M. R. S. Mapeamento e dinâmica das pastagens por meio de séries temporais do sensor Modis, no estado de São Paulo. 2017. 104 f. Tese de Doutorado. Universidade Estadual de Campinas. Campinas, 2017.

PROGRAMA MUNICÍPIOS VERDES - PMV. Municípios verdes. Disponível em:http://www.municipiosverdes.pa.gov. br/pages/quem somos. Acesso em: 10 de março de 2017.

RUDORFF, B. F. T.; AGUIAR, D. A.; SILVA, W. F.; SUGAWARA, L. M.; ADAMI, M.; MOREIRA, M. A. Studies on the rapid expansion of sugarcane for ethanol production in São Paulo state (Brazil) using Landsat data. Remote Sensing, v. 2, n. 4, p. 1057-1076, 2010.
SAATH, K. C. O. Crescimento da demanda mundial de alimentos e as limitações do fator terra no Brasil. 2016. 103 f. Tese de Doutorado. Universidade Federal de Santa Catarina. Florianópolis, 2016.

SAWYER, D. Climate change, biofuels and eco-social impacts in the Brazilian Amazon and Cerrado, Philosophical Transaction Research Society, 363, p. 1747-1752. 2008.

SILVA, A. R.; SALES, A.; VELOSO, C. A. C. Atributos físicos e disponibilidade de carbono do solo em sistemas de integração Lavoura-Pecuária-Floresta (iLPF), Homogêneo e Santa Fé, no estado do Pará, Brasil. Agropecuária Técnica, v. 37, n. 1, 2016.

SOUZA, R. da S.; WANDER, A. E. Aspectos econômicos da produção de feijão no Brasil. Revista de Política Agrícola, v. 23, n. 3, p. 43-54, 2014.

VALENTIM, J. F.; ANDRADE, C. M. S. de. Tendências e perspectivas da pecuária bovina na amazônia brasileira. Amazônia: Ciência \& Desenvolvimento, Belém, v. 4, n. 8, jan./jun. 2009. 